\title{
Frontotemporal Lobar Degeneration
}

\author{
Keith A. Josephs, MST, MD \\ Department of Neurology, Divisions of Behavioral Neurology \& Movement Disorders, Mayo Clinic \\ and Mayo Foundation, Rochester, MN, U.S.A
}

\section{Synopsis}

Frontotemporal lobar degeneration (FTLD) is a syndromic diagnosis that encompasses at least three different variants. Imaging modalities are clinically useful in FTLD while pathology remains the gold standard for definitive diagnosis. To date three different genes have been identified that account for FTLD.

\begin{abstract}
Keywords
Frontotemporal lobar degeneration; semantic dementia; progressive aphasia; progranulin; tau; ubiquitin
\end{abstract}

\section{Historical Perspective}

The clinical syndrome associated with FTLD was first described by Arnold Pick in $1892^{1}$. However, it wasn't until almost 20 years later that the histopathology was described by Alois Alzheimer in $1911^{2}$. He showed an absence of the senile plaques and neurofibrillary tangles that were characteristic of Alzheimer's disease (AD), as well as rounded inclusions today known as Pick bodies, and balloon cells today known as Pick cells. While the term Pick disease was first adopted to describe lobar atrophy it is now reserved for one specific type of pathology.

Interest in FTLD waned until the 1980's when the first diagnostic criteria were proposed by investigators in Lund and Manchester, and the term frontotemporal dementia was adopted to describe cases with behavioral and language impairment associated with frontal and temporal lobe atrophy ${ }^{3}$. These criteria were further refined by Neary and colleagues in $1998^{4}$ when the term FTLD was designated to encompass three clinical variants: frontotemporal dementia (FTD) characterized by prominent behavioral changes, semantic dementia (SD) characterized by a loss of word meaning, and progressive non-fluent aphasia (PNFA) characterized by agrammatic non-fluent speech. In addition, the term primary progressive aphasia (PPA) was coined in the United States by Mesulam in $1982^{5}$, to describe patients that presented with an isolated language impairment of word usage and comprehension. It is now recognized that there is overlap between PNFA and PPA, and between SD and PPA ${ }^{6}$. More recently there has been recognition as well that FTLD can overlap with other well recognized clinical syndromes including corticobasal syndrome (CBS) and progressive supranuclear palsy (PSP) $7-10$. The

Correspondence to: Keith A. Josephs, MST, MD, Department of Neurology, Mayo Clinic \& Mayo Foundation, $2001^{\text {St }}$ Street S.W., Rochester, MN 55905, Tele: (507)-538-1038, Fax: (507)-538-6012, email: E-mail: josephs.keith@ mayo.edu.

Disclosure: The author has nothing to disclosure

Publisher's Disclaimer: This is a PDF file of an unedited manuscript that has been accepted for publication. As a service to our customers we are providing this early version of the manuscript. The manuscript will undergo copyediting, typesetting, and review of the resulting proof before it is published in its final citable form. Please note that during the production process errors may be discovered which could affect the content, and all legal disclaimers that apply to the journal pertain. 
term Pick Complex was proposed by Kertesz as a term to encompass all variants of FTLD, CBS and $\mathrm{PSP}^{11}$.

One of the most important developments in the field of FTLD has been the recognition that mutations in the tau gene and mutations in the progranulin gene, both located on chromosome 17, cause FTLD. Hutton and colleagues demonstrated that mutations in the microtubule associated protein tau (MAPT) causes FTLD with pathological findings of tau deposition in neurons and glia ${ }^{12}$. Again, Hutton and colleagues demonstrated that mutations in the progranulin gene (PGRN) are a cause of FTLD without tau inclusions, but with ubiquitin-only immunoreactive inclusions (FTLD-U) ${ }^{13}$. Recently researchers from the University of Pennsylvania identified the major protein in tau-negative FTLD. This protein, TDP-43, was found in FTLD-U, as well as in cases with motor neuron disease (MND) ${ }^{14}$.

\section{Syndromic Disgnosis}

There are three main clinical variants of FTLD which are based on consensus statements from an international conference on FTLD ${ }^{4}$. These three syndromes are the behavioral variant of frontotemporal dementia (bvFTD), progressive non-fluent aphasia (PNFA), and semantic dementia (SD). In addition to these three syndromes FTLD has been linked with CBS, PSP, apraxia of speech (AOS), and MND.

\section{Behavioral variant frontotemporal dementia}

Of all the variants of FTLD the most common variant is bvFTD ${ }^{15}$, characterized by a significant change in the patients personality and social behavior, and impaired executive function. Patients with bvFTD usually present with behavioral alterations that are different from their usual personal and social behaviors. This includes becoming either more apathetic, or more disinhibited. The apathetic patients usually present in a somewhat depressed like state and lack motivation. These patients are also often hypersomnolent. The disinhibited patients usually present with excessive restlessness, wandering, and socially inappropriate behavior, for example making inappropriate conversations in an elevator or in a restaurant with a stranger. Other features of bvFTD include a lack of concern about ones appearance, as well as a lack of insight into ones illness. Increased jocularity, spontaneous giggling or laughter, unusual eating and oral behaviors, for example gluttony with cramming food into the mouth and eating nonedible food, hypersexuality, hyper-religiosity and perseverative and utilization behavior (the need to play with objects that are in ones visual sight or environment) can also occur. Repetitive behaviors and compulsions may develop later in the disease course although there are rare occurrences of compulsions being the presenting symptom of bvFTD ${ }^{16}$. For example, one patient with bvFTD would go to the bathroom to urinate every 5 minutes of each day. Stereotypic behaviors occur in bvFTD, and they take the form of repetitive behaviors, for example rubbing ones leg ${ }^{17}$. Paranoia, aggressiveness, selfishness, and lack of empathy can occur. Neuropsychological testing in patients with bvFTD may show abnormalities in tests of executive function ${ }^{18}$. However, many subjects with bvFTD may perform normally in neuropsychological testing reflecting the insensitivity of test batteries to detect deficits. Language impairment can occur early in the course of the illness in bvFTD but tends to be less prominent than the behavioral features ${ }^{4}$. Parkinsonism occurs in a subset of patient with bvFTD but tends to be a late feature ${ }^{19}$.

\section{Progressive non-fluent aphasia}

The second variant of FTLD is PNFA ${ }^{4}$. The characteristic features of PNFA are agrammatism with phonemic paraphasias and anomia, which should be present in isolation during the early stages of the disease. It is quite common however for behavioral abnormalities and executive dysfunction to develop later in the disease course. Patients with PNFA may have difficulty 
with comprehension of sentences that are syntactically complex but should have preservation of single word comprehension. Aphasia can occur in isolation but quite frequently coexists with AOS (defined below). Agrammatism is defined as either making grammatical errors while speaking, such as the exclusion or incorrect use of articles, propositions, or verbs. Phonemic paraphasic errors refer to the transposition of phonemes and can be particularly prominent while the patient is reading, where there can be many phonemic paraphasias, for example, slissors for scissors. Another terminology that significantly overlaps with PNFA is that of primary progressive aphasia, or PPA, which refers to the presence of isolated language impairment, fluent or non-fluent, for the first two years of the disease course 5,20 . One study has also suggested that a subset of PPA cases have a different pattern of atrophy and may represent a separate syndrome know as 'logopenic' $\mathrm{PPA}^{21}$.

\section{Semantic dementia}

Semantic dementia (SD) is also referred to as the temporal variant of FTLD ${ }^{4,22}$. In SD there is a progressive loss of word knowledge and meaning, that is, knowledge about objects, facts, and even people. Speech tends to be fluent but may not be meaningful. Comprehension is impaired at the single word level which differs from PNFA where comprehension is affected at the sentence level. Anomia is prominent; however the inability to name an object is matched by the patient's inability to give a detailed description of the object. In addition, patients with SD have a significant visual associative agnosia (impaired object recognition) and therefore may not be able to recognize objects that are presented visually 23 . Therefore, word-picture matching tasks are performed poorly. Food preferences and preoccupation with cross-word puzzles are also common. There is evidence of a surface dyslexia while reading (incorrect pronunciation of orthographically irregular words, for example, yacht is pronounces ya-ch). The majority of cases with SD show temporal lobe atrophy, although on careful inspection the atrophy tends to be asymmetric, more frequently affecting left greater than right temporal lobe ${ }^{22}$. When the right temporal lobe is more severely affected than the left the presenting features tend to be different from those typically seen in left-sided patients. In the patients with more right sided atrophy, prosopagnosia (impaired facial recognition) and geographic disorientation are present, and the patients tend to have behavioral abnormalities including social awkwardness and rudeness.

\section{Corticobasal syndrome}

Corticobasal syndrome ${ }^{24}$ has been linked with FTLD since patients with CBS can evolve and develop behavioral features, personality changes, and executive dysfunction similar to those observed in bvFTD 9 . This syndrome is characterized by asymmetric cortical (apraxia, cortical sensory loss, myoclonic jerks), and basal ganglia (bradykinesia, rigidity, tremor, dystonia) features ${ }^{24}$. Very rarely, patients may develop an alien limb phenomenon in which there is involuntary movements and personification of the limb. Symptoms do not respond to Levodopa treatment. The CBS may develop in patients who initially had features most characteristic of bvFTD, and is even more likely to develop in patients that initially present with PNFA ${ }^{9}$. There is also significant overlap between CBS and PSP. Initially CBS was felt to be specific to corticobasal degeneration pathology, however studies have demonstrated that CBS is nonspecific and can occur as a result of any one of the pathologies that are discussed below 25 .

\section{Progressive supranuclear palsy (PSP)}

Progressive supranuclear palsy, or Steele-Richardson Olszewski syndrome, is characterized by early falls, vertical, especially down gaze, supranuclear palsy, axial greater than appendicular rigidity, and levodopa resistance ${ }^{26}$. Behavior and personality changes are less common and less severe than in CBS. Neuropsychological testing demonstrates some mildto-moderate frontal lobe deficiencies. Patients may present with a non-fluent aphasia with 
prominent AOS and only very late in the disease course show signs characteristic of PSP 27,

28 . These patients tend to have PSP pathology. There have also been reports of an overlap syndrome between PSP and upper motor neuron disease ${ }^{29}$.

\section{Motor neuron disease}

Motor neuron disease (MND) is defined as any evidence of pyramidal tract degeneration or anterior horn cell disease. Motor neuron disease can be isolated to the pyramidal tract (upper MND), anterior horn cells (lower MND), or mixed (amyotrophic lateral sclerosis). MND infrequently coexists with FTLD. This occurs most frequently with bvFTD, but has also been infrequently reported to coexist with PNFA and SD. Typically in these cases there are findings of lower MND or mixed upper and lower MND ${ }^{30}$. Pathology in these cases almost always shows evidence of lobar degeneration as well as MND. However, not all pathologically confirmed cases show evidence of clinical MND ${ }^{30}$. Clinical studies have identified a higher than expected frequency of MND in FTLD subjects, conversely a high frequency of frontal lobe dysfunction on neuropsychological tests has been observed in subjects with MND $^{31}$, 32 .

\section{Apraxia of Speech}

Apraxia of speech (AOS) is also referred to as speech apraxia, aphemia, and phonetic disintegration. It is defined as a motor speech disorder with a slow speaking rate, abnormal prosody, and distorted sound substitutions, repetitions, and prolongations, at times accompanied by groping. It is common to lump AOS under the heading of PNFA in neurodegenerative diseases, however AOS can occur in the absence of aphasia and is considered a separate syndrome by some researchers ${ }^{27}$. Imaging studies have identified specific anatomical correlates of AOS, distinct from those observed in PNFA 27. Clinicopathological studies have suggested that the presence of AOS is specific to tau biochemistry 27 .

\section{Ancillary Testing}

\section{Routine blood tests}

Patients presenting with an FTLD syndrome should undergo routine blood tests. These include a complete blood count, electrolytes, thyroid function studies, liver function tests, and renal function tests, to rule out systemic illnesses causing a dementia. In very young patients, especially where there is diagnostic uncertainty, more elaborate testing may be required for diagnosis. Some of these tests may include screening for metabolic, genetic, and autoimmune disorders.

\section{Cerebrospinal fluid}

Cerebrospinal fluid (CSF) studies in FTLD are useful to exclude other causes of dementia. In the majority of cases of FTLD there can be elevated protein however the rest of the profile tends to be within normal limits. Oligoclonal bands are not present. Recent studies have investigated the diagnostic utility of tau, amyloid beta 42, and neurofilament. Phosphorylated tau protein have been reported to be elevated ${ }^{33}$, but also have been reported to be normal ${ }^{34}$. Total tau levels have been reported to be $\mathrm{low}^{34}$ or normal ${ }^{35}$. Some researchers have suggested that a combination of CSF tau and amyloid beta 42 may help differentiate FTLD from AD

36. Reports aiming to differentiate AD from FTLD by measuring neurofilament proteins have been conducted, ${ }^{35,37}$ but need to be validated. 


\section{Electroencephalogram}

An EEG is often performed as part of the clinical evaluation in FTLD. This is also important to rule out other causes of dementia, for example transient epileptic phenomena. There are however no specific EEG findings in FTLD and recently it was shown that there are no EEG abnormalities that are useful in differentiating FTLD from $\mathrm{AD}^{38}$.

\section{Neuroimaging}

Patients show atrophy and hypometabolism of the frontal and temporal cortices, which matches the pathological findings. The occipital lobe is almost always spared, although the parietal lobe can be affected, especially in subjects that present with PNFA or CBS. The presence of frontal and anterior temporal lobe abnormalities on brain imaging is part of the diagnostic criteria for FTLD $^{4}$. It should be noted however that there are cases of FTLD who even after more than ten years of illness duration may show very little atrophy 39 . There are characteristic patterns of atrophy that have been suggested for each of the syndromic variants of FTLD and their related disorders. Subjects presenting with bvFTD usually show symmetric frontal lobe atrophy (Figure 1), although asymmetric right sided atrophy has been reported ${ }^{40}$. Studies using automated image analysis techniques have allowed a more detailed assessment of patterns of atrophy, and have shown atrophy in a network of limbic areas that are likely to be involved in the fine tuning of behavior, including the ventromedial cortex, anterior cingulate and amygdala $^{41,42}$. It seems to be becoming clearer however that subjects with frontal lobe features suggestive of bvFTD could also have right temporal lobe atrophy. Functional imaging studies have shown hypometabolism (Figure 2) or hypoperfusion in the same anatomical regions.

In contrast, patients with SD show atrophy and hypometabolism predominantly in the left anterior temporal lobe. However patients may present with more right temporal lobe atrophy (Figure 1). Practically all left temporal lobe regions can be involved, with particularly severe atrophy in inferior temporal regions, including the fusiform and inferior temporal gyrus, with relative sparing of the superior temporal gyrus 43,44 . Atrophy significantly affects the hippocampus and amygdala ${ }^{43}$. There is also often involvement of the ventromedial and superior frontal lobes, which is consistent with the fact that patients with SD often develop behavioral abnormalities. There is also evidence that as the disease progresses the atrophy can extend from the left anterior temporal lobe to involve more posterior temporal regions, the inferior frontal lobe and the right anterior temporal lobe 45 .

Unlike SD, patients with PNFA have consistently shown left frontal and perisylvian atrophy on magnetic resonance imaging (MRI) (Figure 1), with hypoperfusion and hypometabolism demonstrated in the same regions on functional imaging. In those that have become mute a pattern of atrophy affecting the left perisylvian region and extending into the left basal ganglia has been demonstrated ${ }^{46}$.

Imaging studies have also been completed in other syndromic variants associated with FTLD. Posterior frontal and superior parietal atrophy is associated with $\mathrm{CBS} 47,48$, while those with PSP show areas of subcortical atrophy affecting the superior cerebellar peduncle and midbrain 48,49 . The anterior-posterior diameter of the midbrain is reduced ${ }^{50}$ giving the so called "face of Mickey mouse" appearance. Patients with AOS show atrophy of the supplemental motor area and superior posterior frontal lobe 27 . The logopenic variant of primary progressive aphasia was reported to be associated with left posterior temporal and inferior parietal lobule atrophy ${ }^{51}$. Subjects that present with prosopagnosia have shown predominantly right temporal lobe atrophy (Figure 1). This pattern of atrophy can also be seen in patients that present with predominant behavior features, as well as those with prominent geographic disorientation. 
Recent studies have suggested that the pathological subtypes of FTLD may also have characteristic imaging findings. Patients with FTLD-U (defined below) have been shown to have predominant atrophy of the temporal lobes, particularly in posterior gyri, as well as some involvement of the frontal lobes, while patients with FTLD-MND show patterns of atrophy relatively restricted to just the frontal lobes ${ }^{52}$. Patients with PiD show severe involvement of the frontal lobes 53 .

\section{Pathology}

The gross pathologic findings in FTLD are similar to MRI findings in FTLD. There is atrophy affecting the frontal and temporal lobes (Figure 3 ) and in some cases the parietal lobes. The occipital lobes are almost always spared. The frontal, temporal and parietal lobes can all be affected however it is most common to find varying degrees of atrophy in each region, at times correlating with the presenting syndromes. Histological diagnosis in FTLD however is heterogenous ${ }^{54}$. The presence or absence of tau-positive inclusions is used to simplify the classification and to determine if the case is reported as a tauopathy (tau-positive inclusions are the major findings) or a non-tauopathy (tau-positive inclusions are minor or absent). The major diagnostic tauopathies that underlie FTLD are corticobasal degeneration (CBD), progressive supranuclear palsy (PSP) and Pick disease (PiD). They all differ by the distribution of the pathology and the morphological features of the tau positive inclusions. Corticobasal degeneration was originally thought to be only associated with the CBS however has been found to underlie many other syndromes, especially PNFA ${ }^{55}$. And while PSP was originally associated with the clinical syndrome of early falls, parkinsonism, and supranuclear gaze palsy, recent evidence have shown that PSP pathology can be found in subjects with PNFA especially when AOS is also present ${ }^{27}$. Pick disease is less common than PSP and CBD in FTLD pathological studies $7-10$.

The two major non-tauopathies include those with ubiquitin-only immunoreactive changes (FTLD-U), and those with motor neuron disease (FTLD-MND). The former, FTLD-U, is the most common pathology that underlies FTLD 56,57 . In addition, FTLD-U is the most common pathology in the SD variant of FTLD ${ }^{8}, 58$. There are many different terminologies that have been used to describe this pathology (Table 1) and the presence of intranuclear inclusions in FTLD-U is associated with familial FTLD and may suggest a mutation in the PGRN gene ${ }^{59}$. Similar to the many terminologies that define FTLD-U, many terminologies also define FTLDMND (Table 1). Unlike in FTLD-U where there is no evidence of motor neuron disease (MND), FTLD-MND is characterized by pathological findings of MND. When there is clinical evidence of MND pathological diagnosis of FTLD-MND has been shown to be $100 \%$ sensitive $^{8}$. A recent discovery is the identification that a protein TDP-43 may be the major component of neuronal inclusions in FTLD-U and FTLD-MND however this remains to be validated ${ }^{14}$. Two other non-tauopathies worth mentioning are neurofilament inclusion body disease(NIBD) 60 and dementia lacking distinctive histology (DLDH) which is characterized by neuronal loss and gliosis affecting frontal and temporal cortex, but absence of any intraneuronal inclusions ${ }^{19}$.

\section{Genetics}

A positive family history of dementia occurs in approximately $40 \%$ of patients with FTLD. In the majority of these families, the pattern of inheritance has been autosomal dominant. Genetic studies have identified a loci on chromosome 9q, and genes on chromosome 3p and 17q. The first gene to be identified and linked to familial FTLD was the microtubule associated protein tau (MAPT) gene located on chromosome $17^{12}$. Due to a consensus conference in 1996 cases linked to tau on chromosome $17 \mathrm{q} 21$ were termed frontotemporal dementia with parkinsonism linked to chromosome 17 (FTDP-17). To date approximately 35 different confirmed mutations 
in MAPT have been identified in over 100 families. Pathologically, patients with FTLD and MAPT mutations reveal tau-positive inclusions. The second gene to be linked with FTLD is the $C H M P 2 B$ gene (charged multivesicular body protein also known as chromatin-modifying protein $2 \mathrm{~B})^{61}$. This gene has been linked to a family from the Jutland region of Denmark which initially was thought to be associated with DLDH pathology. Recent reevaluation of some of the subjects from this family have, however, identified ubiquitin positive inclusions. Mutations in $C H M P 2 B$ are however a rare cause of FTLD, and were not identified in 141 familial probands from the USA and $\mathrm{UK}^{62}$. The most recent gene identified that causes FTLD is progranulin $(P G R N)^{13,63}$. Mutations in the PGRN gene are more common than the prior two mutations. Mutations in PGRN have been reported to account for approximately $10 \%$ of subjects with FTLD, and $25 \%$ of those with a positive family history of dementia ${ }^{64}$. Pathological diagnosis in subjects with a $P G R N$ mutation has consistently been found to be FTLD-U without any evidence of MND 59,65 . Clinical studies have suggested that patients with PGRN mutation have more frequent parkinsonism and language impairment than subjects without a mutation. Imaging and pathological studies have suggested that FTLD-U subjects with a PGRN mutation have a more severe pattern of atrophy, particularly affecting the frontal and parietal lobes, than FTLD-U subjects without PGRN mutations ${ }^{66}$. Frontotemporal lobar degeneration with MND has been linked to chromosome $9 \mathrm{p}$ in two large families 65,67 .

\section{Treatment}

Pharmacological treatment for FTLD is limited to addressing behavioral dyscontrol. These studies have focused mainly on drugs with serotonergic modulated properties. Treatment trials using serotonin reuptake inhibitors have had at best, modest effects 68,69 .

While there are no specific pharmacological treatments for aphasia many patients may benefit from speech therapy which aid in their ability to communicate with family and friends. Because speech therapy may be more beneficial for certain aspects of the language impairment proper syndromic diagnosis and recognition of important signs and symptoms, especially dysarthria that accompany the aphasia, is important.

\section{Summary}

Frontotemporal lobar degeneration is a syndromic diagnosis that includes at least three different syndromes: bvFTD, SD and PNFA. There is also significant overlap between FTLD, PSP, CBS, AOS, and MND suggesting possible common etiopathogenesis. Imaging modalities are helpful in differentiate FTLD from other causes of dementia and usually show a pattern of frontotemporal and parietal abnormalities depending on which syndrome is the most prominent. Pathology remains the gold standard for definitive diagnosis but is heterogeneous. The most common pathology has been identified as FTLD-U. Recent studies have demonstrated that mutations in the PGRN gene are associated with FTLD-U pathology. Two additional genes that are associated with FTLD are the MAPT and $C H M P 2 B$ genes. A genetic loci has been mapped to chromosome 9p is families in which FTLD and MND overlap. Treatment in FTLD is at best modest.

\section{Acknowledgments}

KAJ is supported by the NIH Roadmap Multidisciplinary Clinical Research Career Development Award Grant (K12/ NICHD)-HD49078 (KAJ), and the Robert H. and Clarice Smith and Abigail Van Buren Alzheimer's Disease Research Program of the Mayo Foundation, U.S.A.

The author would like to acknowledge Dr. Jennifer $\mathrm{L}$. Whitwell for critical review and aid with manuscript preparation, and Dr. Dennis W. Dickson for Figure 3. 


\section{References}

1. Pick A. Uber die Beziehungen der senilen Hirantropie zur aphasie. Prager Medizinishe Wochenscrift 1892;17:165-167.

2. Alzheimer A. Uber eigenartige Krankheitsfalle des spateren Alters. Zeitscrift fur die Gesamte Neurologie und Psychiatrie 1911;4:356-385.

3. Brun A. Clinical and neuropathological criteria for frontotemporal dementia. The Lund and Manchester Groups. J Neurol Neurosurg Psychiatry 1994;57:416-418. [PubMed: 8163988]

4. Neary D, Snowden JS, Gustafson L, et al. Frontotemporal lobar degeneration: a consensus on clinical diagnostic criteria. Neurology 1998;51:1546-1554. [PubMed: 9855500]

5. Mesulam MM. Slowly progressive aphasia without generalized dementia. Ann Neurol 1982;11:592598. [PubMed: 7114808]

6. Adlam AL, Patterson K, Rogers TT, et al. Semantic dementia and fluent primary progressive aphasia: two sides of the same coin? Brain 2006;129:3066-3080. [PubMed: 17071925]

7. Hodges JR, Davies RR, Xuereb JH, et al. Clinicopathological correlates in frontotemporal dementia. Ann Neurol 2004;56:399-406. [PubMed: 15349867]

8. Josephs KA, Petersen RC, Knopman DS, et al. Clinicopathologic analysis of frontotemporal and corticobasal degenerations and PSP. Neurology 2006;66:41-48. [PubMed: 16401843]

9. Kertesz A, McMonagle P, Blair M, et al. The evolution and pathology of frontotemporal dementia. Brain 2005;128:1996-2005. [PubMed: 16033782]

10. Forman MS, Farmer J, Johnson JK, et al. Frontotemporal dementia: clinicopathological correlations. Ann Neurol 2006;59:952-962. [PubMed: 16718704]

11. Kertesz A, Hudson L, Mackenzie IR, Munoz DG. The pathology and nosology of primary progressive aphasia. Neurology 1994;44:2065-2072. [PubMed: 7969961]

12. Hutton M, Lendon CL, Rizzu P, et al. Association of missense and 5 '-splice-site mutations in tau with the inherited dementia FTDP-17. Nature 1998;393:702-705. [PubMed: 9641683]

13. Baker M, Mackenzie IR, Pickering-Brown SM, et al. Mutations in progranulin cause tau-negative frontotemporal dementia linked to chromosome 17. Nature 2006;442:916-919. [PubMed: 16862116]

14. Neumann M, Sampathu DM, Kwong LK, et al. Ubiquitinated TDP-43 in frontotemporal lobar degeneration and amyotrophic lateral sclerosis. Science 2006;314:130-133. [PubMed: 17023659]

15. Johnson JK, Diehl J, Mendez MF, et al. Frontotemporal lobar degeneration: demographic characteristics of 353 patients. Arch Neurol 2005;62:925-930. [PubMed: 15956163]

16. Mendez MF, Perryman KM, Miller BL, et al. Compulsive behaviors as presenting symptoms of frontotemporal dementia. J Geriatr Psychiatry Neurol 1997;10:154-157. [PubMed: 9453681]

17. Mendez MF, Shapira JS, Miller BL. Stereotypical movements and frontotemporal dementia. Mov Disord 2005;20:742-745. [PubMed: 15786492]

18. Johanson A, Hagberg B. Psychometric characteristics in patients with frontal lobe degeneration of non-Alzheimer type. Arch Gerontol Geriatr 1989;8:129-137. [PubMed: 2735785]

19. Knopman DS, Mastri AR, Frey WH 2nd, et al. Dementia lacking distinctive histologic features: a common non-Alzheimer degenerative dementia. Neurology 1990;40:251-256. [PubMed: 2300243]

20. Mesulam MM. Primary progressive aphasia. Ann Neurol 2001;49:425-432. [PubMed: 11310619]

21. Gorno-Tempini ML, Dronkers NF, Rankin KP, et al. Cognition and anatomy in three variants of primary progressive aphasia. Annals of Neurology 2004;55:335-346. [PubMed: 14991811]

22. Thompson SA, Patterson K, Hodges JR. Left/right asymmetry of atrophy in semantic dementia: behavioral-cognitive implications. Neurology 2003;61:1196-1203. [PubMed: 14610120]

23. Snowden JS. Semantic dementia: a form of circumscribed cerebral atrophy. Behavioural Neurology 1989;2:167-182.

24. Boeve BF, Lang AE, Litvan I. Corticobasal degeneration and its relationship to progressive supranuclear palsy and frontotemporal dementia. Ann Neurol 2003;54:S15-19. [PubMed: 12833363]

25. Boeve BF, Maraganore DM, Parisi JE, et al. Pathologic heterogeneity in clinically diagnosed corticobasal degeneration. Neurology 1999;53:795-800. [PubMed: 10489043] 
26. Litvan I, Agid Y, Calne D, et al. Clinical research criteria for the diagnosis of progressive supranuclear palsy (Steele-Richardson-Olszewski syndrome): report of the NINDS-SPSP international workshop. Neurology 1996;47:1-9. [PubMed: 8710059]

27. Josephs KA, Duffy JR, Strand EA, et al. Clinicopathological and imaging correlates of progressive aphasia and apraxia of speech. Brain 2006;129:1385-98. [PubMed: 16613895]

28. Josephs KA, Boeve BF, Duffy JR, et al. Atypical progressive supranuclear palsy underlying progressive apraxia of speech and nonfluent aphasia. Neurocase 2005;11:283-296. [PubMed: 16093229]

29. Josephs KA, Katsuse O, Beccano-Kelly DA, et al. Atypical progressive supranuclear palsy with corticospinal tract degeneration. J Neuropathol Exp Neurol 2006;65:396-405. [PubMed: 16691120]

30. Josephs KA, Parisi JE, Knopman DS, et al. Clinically undetected motor neuron disease in pathologically proven frontotemporal lobar degeneration with motor neuron disease. Arch Neurol 2006;63:506-512. [PubMed: 16606762]

31. Lomen-Hoerth C, Anderson T, Miller B. The overlap of amyotrophic lateral sclerosis and frontotemporal dementia. Neurology 2002;59:1077-1079. [PubMed: 12370467]

32. Lomen-Hoerth C, Murphy J, Langmore S, et al. Are amyotrophic lateral sclerosis patients cognitively normal? Neurology 2003;60:1094-1097. [PubMed: 12682312]

33. Arai H, Morikawa Y, Higuchi M, et al. Cerebrospinal fluid tau levels in neurodegenerative diseases with distinct tau-related pathology. Biochem Biophys Res Commun 1997;236:262-264. [PubMed: 9240421]

34. Grossman M, Farmer J, Leight S, et al. Cerebrospinal fluid profile in frontotemporal dementia and Alzheimer's disease. Ann Neurol 2005;57:721-729. [PubMed: 15852395]

35. Sjogren M, Minthon L, Davidsson P, et al. CSF levels of tau, beta-amyloid(1-42) and GAP-43 in frontotemporal dementia, other types of dementia and normal aging. J Neural Transm 2000;107:563579. [PubMed: 11072752]

36. Riemenschneider M, Wagenpfeil S, Diehl J, et al. Tau and Abeta42 protein in CSF of patients with frontotemporal degeneration. Neurology 2002;58:1622-1628. [PubMed: 12058089]

37. Rosengren LE, Karlsson JE, Sjogren M, et al. Neurofilament protein levels in CSF are increased in dementia. Neurology 1999;52:1090-1093. [PubMed: 10102440]

38. Chan D, Walters RJ, Sampson EL, et al. EEG abnormalities in frontotemporal lobar degeneration. Neurology 2004;62:1628-1630. [PubMed: 15136699]

39. Josephs K, Whitwell JL, Jack CR Jr, Dickson DW. Frontotemporal lobar degeneration without lobar atrophy. Arch Neurol. 2006In press

40. Fukui T, Kertesz A. Volumetric study of lobar atrophy in Pick complex and Alzheimer's disease. J Neurol Sci 2000;174:111-121. [PubMed: 10727696]

41. Boccardi M, Sabattoli F, Laakso MP, et al. Frontotemporal dementia as a neural system disease. Neurobiol Aging 2005;26:37-44. [PubMed: 15585344]

42. Rosen HJ, Gorno-Tempini ML, Goldman WP, et al. Patterns of brain atrophy in frontotemporal dementia and semantic dementia. Neurology 2002;58:198-208. [PubMed: 11805245]

43. Chan D, Fox NC, Scahill RI, et al. Patterns of temporal lobe atrophy in semantic dementia and Alzheimer's disease. Annals of Neurology 2001;49:433-442. [PubMed: 11310620]see comment

44. Mummery CJ, Patterson K, Price CJ, et al. A voxel-based morphometry study of semantic dementia: relationship between temporal lobe atrophy and semantic memory. Ann Neurol 2000;47:36-45. [PubMed: 10632099]

45. Whitwell JL, Anderson VM, Scahill RI, et al. Longitudinal patterns of regional change on volumetric MRI in frontotemporal lobar degeneration. Dementia \& Geriatric Cognitive Disorders 2004; 17:307310. [PubMed: 15178942]

46. Gorno-Tempini ML, Ogar JM, Brambati SM, et al. Anatomical correlates of early mutism in progressive nonfluent aphasia. Neurology. 2006

47. Boxer AL, Geschwind MD, Belfor N, et al. Patterns of brain atrophy that differentiate corticobasal degeneration syndrome from progressive supranuclear palsy. Arch Neurol 2006;63:81-86. [PubMed: 16401739] 
48. Josephs K, Whitwell JL, Dickson D, et al. Voxel-based morphometry in autopsy proven PSP and CBD. Neurobiol Aging. 2006Epub

49. Paviour DC, Price SL, Stevens JM, et al. Quantitative MRI measurement of superior cerebellar peduncle in progressive supranuclear palsy. Neurology 2005;64:675-679. [PubMed: 15728291]

50. Righini A, Antonini A, De Notaris R, et al. MR imaging of the superior profile of the midbrain: differential diagnosis between progressive supranuclear palsy and Parkinson disease. AJNR Am J Neuroradiol 2004;25:927-932. [PubMed: 15205125]

51. Gorno-Tempini ML, Rankin KP, Woolley JD, et al. Cognitive and behavioral profile in a case of right anterior temporal lobe neurodegeneration. Cortex 2004;40:631-644. [PubMed: 15505973]

52. Whitwell JL, Jack CR Jr, Senjem ML, Josephs KA. Patterns of atrophy in pathologically confirmed FTLD with and without motor neuron degeneration. Neurology 2006;66:102-104. [PubMed: 16401855]

53. Whitwell JL, Josephs KA, Rossor MN, et al. Magnetic resonance imaging signatures of tissue pathology in frontotemporal dementia. Arch Neurol 2005;62:1402-1408. [PubMed: 16157747]

54. McKhann GM, Albert MS, Grossman M, et al. Clinical and pathological diagnosis of frontotemporal dementia: report of the Work Group on Frontotemporal Dementia and Pick's Disease. Arch Neurol 2001;58:1803-1809. [PubMed: 11708987]

55. McMonagle P, Blair M, Kertesz A. Corticobasal degeneration and progressive aphasia. Neurology 2006;67:1444-1451. [PubMed: 17060571]

56. Josephs KA, Holton JL, Rossor MN, et al. Frontotemporal lobar degeneration and ubiquitin immunohistochemistry. Neuropathology \& Applied Neurobiology 2004;30:369-373. [PubMed: 15305982]

57. Lipton AM, White CL 3rd, Bigio EH. Frontotemporal lobar degeneration with motor neuron diseasetype inclusions predominates in 76 cases of frontotemporal degeneration. Acta Neuropathol (Berl) 2004;108:379-385. [PubMed: 15351890]

58. Knibb JA, Xuereb JH, Patterson K, Hodges JR. Clinical and pathological characterization of progressive aphasia. Ann Neurol 2006;59:156-165. [PubMed: 16374817]

59. Josephs K, Ahmed Z, Katsuse O, et al. Neuropathological features of progranulin gene (PGRN) mutations. 2007Submitted

60. Josephs KA, Holton JL, Rossor MN, et al. Neurofilament inclusion body disease: a new proteinopathy? Brain 2003;126:2291-2303. [PubMed: 12876145]

61. Skibinski G, Parkinson NJ, Brown JM, et al. Mutations in the endosomal ESCRTIII-complex subunit CHMP2B in frontotemporal dementia. Nat Genet 2005;37:806-808. [PubMed: 16041373]

62. Cannon A, Baker M, Boeve B, et al. CHMP2B mutations are not a common cause of frontotemporal lobar degeneration. Neurosci Lett 2006;398:83-84. [PubMed: 16431024]

63. Cruts M, Gijselinck I, van der Zee J, et al. Null mutations in progranulin cause ubiquitin-positive frontotemporal dementia linked to chromosome 17q21. Nature 2006;442:920-924. [PubMed: 16862115]

64. Gass J, Cannon A, Mackenzie IR, et al. Mutations in progranulin are a major cause of ubiquitinpositive frontotemporal lobar degeneration. Hum Mol Genet 2006;15:2988-3001. [PubMed: 16950801]

65. Morita M, Al-Chalabi A, Andersen PM, et al. A locus on chromosome 9p confers susceptibility to ALS and frontotemporal dementia. Neurology 2006;66:839-844. [PubMed: 16421333]

66. Whitwell JL, Jack CR Jr, Siung M, et al. Voxel based morphometry in progranulin gene (PGRN) mutations. Arch Neurol. 2007

67. Vance C, Al-Chalabi A, Ruddy D, et al. Familial amyotrophic lateral sclerosis with frontotemporal dementia is linked to a locus on chromosome 9p13.2-21.3. Brain 2006;129:868-876. [PubMed: 16495328]

68. Moretti R, Torre P, Antonello RM, et al. Frontotemporal dementia: paroxetine as a possible treatment of behavior symptoms. A randomized, controlled, open 14-month study. Eur Neurol 2003;49:13-19. [PubMed: 12464713]

69. Lebert F, Stekke W, Hasenbroekx C, Pasquier F. Frontotemporal dementia: a randomised, controlled trial with trazodone. Dement Geriatr Cogn Disord 2004;17:355-359. [PubMed: 15178953] 

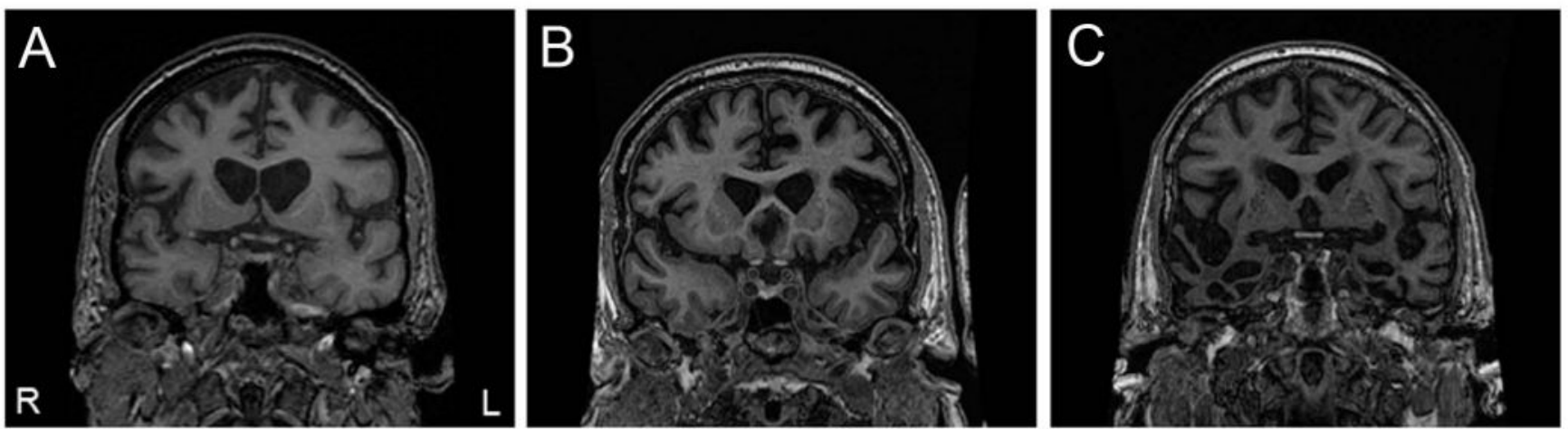

Figure 1.

Coronal T1-weighted MRI scans demonstrating frontal and caudate atrophy in a patient with behavioral changes and a diagnosis of bvFTD (A), left perisylvian atrophy in another patient with non-fluent speech and a diagnosis of PNFA (B) and right > left anterior temporal lobe atrophy in a patient with loss of facial recognition and word meaning and a diagnosis of right temporal variant of SD (C). 


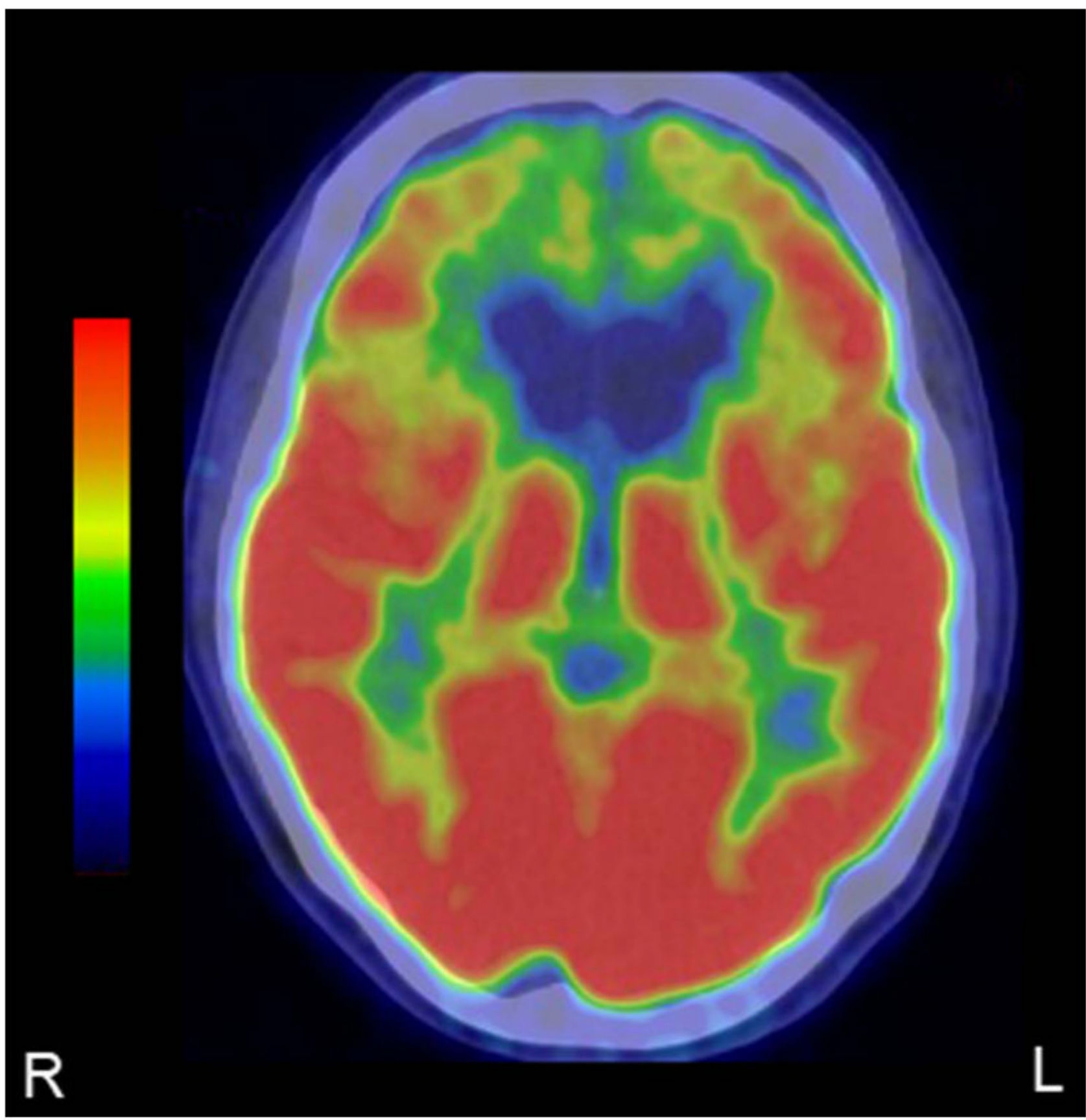

Figure 2.

F-18 fluorodeoxyglucose positive emission tomography (PET) scan demonstrating predominant frontal and some temporal lobe hypometabolism in a patient with personality changes and a diagnosis of bvFTD. 


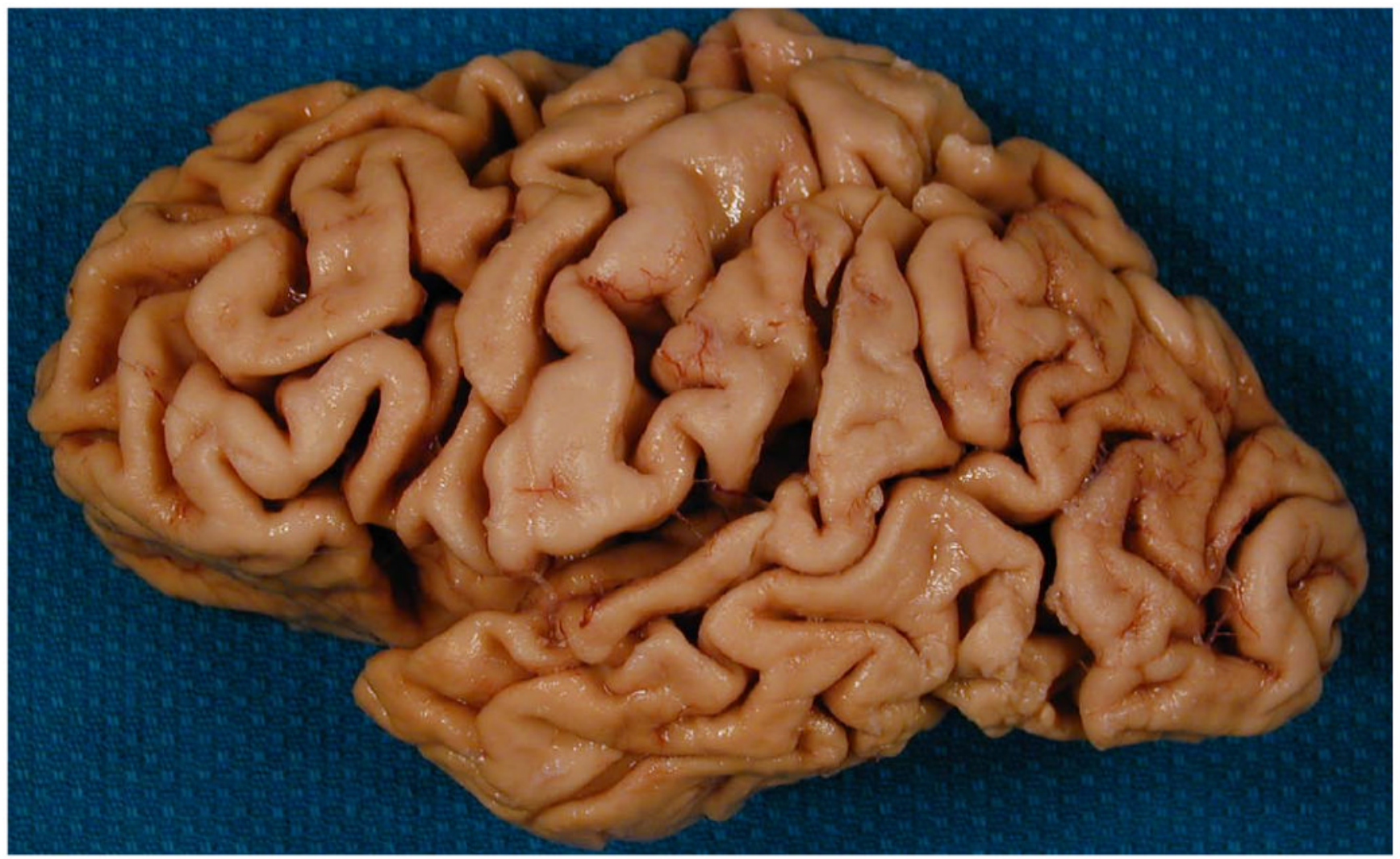

Figure 3.

On gross pathology there is severe frontal lobe atrophy with preserved primary motor and sensory cortex in a patient that had personality changes and executive dysfunction and a diagnosis of bvFTD. 
Table 1

Other pathologic terminologies

FTLD-U

- Motor neuron disease inclusion dementia (MNDID)

- Dementia of motor neuron disease type

- Dementia with ubiquitin inclusion bodies

- Dementia with inclusions tau and synuclein-negative, ubiquitinated (ITSNU)

- Dementia with ubiquitinated inclusions

- $\quad$ Pick complex with ITSNU

- Dementia with ubiquitinated tau-negative non eosinophilic inclusions (UTNNEI)

FTLD-MND

- $\quad$ Pick's disease with ALS

- $\quad$ Frontotemporal dementia with motor neuron disease (FTD-MND)

- $\quad$ Motor neuron disease type dementia (MNDD)

- Dementia with motor neuron disease

- Dementia with ALS

- $\quad$ ALS with dementia

- Presenile dementia with motor neuron disease

- Aphasic dementia and motor neuron disease 